\title{
The Role of Mathematics in Architecture and Fine Arts: A Historical Overview, Problems and Prospects
}

\author{
J. Venetis \\ School of Applied Mathematics and Physical Sciences, NTUA, Section of Mechanics, Athens, Greece
}

Received March 15, 2020; Revised May 16, 2020; Accepted May 20, 2020

Copyright ( $(2020$ by authors, all rights reserved. Authors agree that this article remains permanently open access under the terms of the Creative Commons Attribution License 4.0 International License

\begin{abstract}
In this paper, the author investigates the role and contribution of pure and applied mathematics to architecture and fine arts in a unified manner. To this end, a thorough and explanatory historical overview of this diachronic and interdisciplinary topic, from the ages of ancient Mediterranean cultures to the so-called western civilization of the late twentieth century is presented. In this framework, the author first examines the fundamental role of traditional mathematics (e.g. Descriptive and Projective Geometry) in architectural design and fine arts, and in the sequel the discussion extends to the outstanding contribution of modern and computational mathematics (NURBS, Fractals, Boolean matrices, Graph Theory, etc.) to these issues. Besides, the important role of computer-aided design (CAD) is mentioned and emphasized. Indeed, CAD is an exceptional scientific and technological achievement, the scientific background of which is essentially a combination of Informatics, Discrete Mathematics and Descriptive Geometry. In addition, various existing problems that sometimes hinder the application of the science of mathematics to architecture and the fine arts are highlighted and demonstrated. Finally, given that the most appropriate mathematical background for the graduate studies in architectural schools along with the schools of fine arts is a very difficult and rather questionable issue, some suggestions are made in order to encourage and strengthen the relationship among applied mathematics, architecture and fine arts.
\end{abstract}

Keywords Pure Mathematics, Applied Mathematics, Descriptive Geometry, Projective Geometry, NURBS, Fractals, Boolean Matrices, Architecture, Fine Arts

\section{Introduction}

It is well known that the fundamental science of forms and their order geometry contributes to the process of composition and designing in architecture. Evidently, composition in architecture starts with elements and their relations. Moreover, Geometry is able to make a contribution to this process by dealing with geometric figures and forms as elements as well as proportions, angles and transformations as relations between them. Structures build the foundation of composing, Leopold, (2006). Structures indicate general systems of order in various scientific disciplines, derived from the Latin notion "structura" which means joining together in order. Mathematics can be seen as a general science of structures by considering systems of elements and their relations or operations. The notion of harmony is seen as a fundamental principle of composition in history of architecture. Hence, composition is based on harmony and order as aesthetic categories. The understanding of harmony is based on the mythological person "Harmonia", the goddess of harmony, who was seen as the daughter of Ares, the god of war, and Aphrodite, the goddess of love and beauty. Harmonia is the symbol of the union of antagonisms, Leopold, (2006). Harmony means the connection of different or opposed things to an arranged whole. The antiquity science itself is conducted by principles of harmony and order. In particular, the "Modulor" of Le Corbusier is an example of an architectonic concept of designing and creating according to geometric rules in modern architecture, but it remains bound to the classical conception of harmony, Le Corbusier, (1956).

On the other hand, vernacular architecture is architecture characterized by the use of local materials and knowledge, usually without the supervision of professional architects. Vernacular buildings are typically simple and practical, whether residential houses or built for other purposes, Popescu, (2015).

In the meanwhile, the role of Boolean matrices and planar graphs theory in architectural design was thoroughly investigated by Palla, Palla (2003). 
Specifically, it was shown that the top view of an architectural form may emerge as a succession of finite planar graphs.

Further, fractal geometry, which indeed has many applications to architectural design, is the study of mathematical shapes that display a cascade of never ending, self-similar, meandering details as one observes them more closely [Benoit 1975].

In addition, the NURBS (Non-uniform rational basis spline) are mathematical representations of geometry in 3D able to describe any form accurately, from simple lines in 2D, circles, arches, or curves to the most complex solids or organic surfaces in a freeway in 3D.

Due to their flexibility and precision, model NURBS can be used in any process, from the creation and development to the production of pieces or construction of space surfaces (Chiarella, 2004).

Besides, the role fractal geometry in architectural design was studied by Kitchley, Kitchley (2003) whereas the role of topology in the architectural plan was studied by Aguiar Aguiar, (2003).

Finally, Gül carried out a detailed and remarkable study on several instructional methods used in CAD courses in interior architecture education, (Gül 2015).

In this paper, the role of mathematics in fine arts is examined. In this context, a thorough historical overview of the above relationship, from ancient Mediterranean cultures to the so-called western civilization of the late nineteenth century, is performed. Further, several existing problems are highlighted and finally some suggestions are made to encourage and strengthen the relationship between mathematics and fine arts.

\section{Historical Overview}

i) Pythagorean approach

In the Pythagorean approach all occurrences are seen under a general principle. This principle wants to be a principle of composition by understanding all processes in mathematical orders. Arithmetic, geometry, astronomy and music, i.e. the sciences of Quadrivium are all based on this general principle. Pythagoras was convinced that harmony, all things and principles of being can be grasped by integers and mathematical regularities. He discovered that 3 music intervals form simple relations according the division of the string and the number of oscillations, Choisy (1996, Fletcher, (1998), Recht (1995). The Tetraktys: numbers 1 to 4 (4 elements, 4 cardinal points) form the foundation according to Pythagoras. The idea of harmonic proportions is a general principle for all sciences and applications. The Pythagorean star is another remarkable item. The symbol of the Pythagorean fraternity was "Pentagram", that is, the star formed by its five diagonals of a regular pentagon. It turns out that every side of the "pentagram" divides the other two into golden sections.

ii) Phidias number and Golden Mean

Let us make the following questions:

1 . Which is the unique strictly positive root of the following polynomial equation?

$$
x^{2 n+2}-x^{2 n+1}-x^{2 n}-x^{n+2}+x^{n+1}+x^{n}+x^{2}-x-1=0
$$

2. Is there any strictly positive real number $X$ such that to satisfy the following logarithmic equation?

$$
\frac{\ln x+\ln (1-x)}{\pi}=i
$$

where $i$ is the imaginary unit equal to $\sqrt{-1}$

Evidently according to Euler's identity it implies that

$$
\operatorname{EXP}(i \pi)=i^{2}
$$

3. Divide a segment into two parts. In the sense of Ancient Greek Geometry, we may say that in this way we create a volume which is gold since the ratio of the big one to the small one is equal to the ratio of the whole one to the big one. What is the value of this ratio?

4. Consider a regular decimal inscribed in a circle. Evidently, the radius of the circle is greater than its side. But the question is: How many times?

5. The well known Fibonacci sequence 1, 1, 2, 3, 5, 8, 13, 21, 34, 55, 89, 144, 233, 377, 610, 987, 1597, 2584, 4181, 6765, 10946, 17711, 28657, 46368, 75025.

$$
\mathrm{a}_{\mathrm{n}}=\mathrm{a}_{\mathrm{n}-1}+\mathrm{a}_{\mathrm{n}-2} \forall n \in N^{*}
$$

Now let us consider another sequence named $b_{n}$, the terms of which are the ratios of the successive terms of the above mentioned sequence $a_{n}$.

Thus we can write out

$$
\mathrm{b}_{\mathrm{n}}=1,2, \frac{3}{2}, \frac{5}{3}, \frac{8}{5}, \frac{13}{8}, \frac{31}{13}, \ldots
$$

In this framework, one may prove that the above sequence converges to a strictly positive real number. What is this number?

Phidias number Phi $=\frac{1+\sqrt{5}}{2}$ is the answer to all the above questions.

In the meanwhile, the proportion known as the Golden Mean has always existed in mathematics and in the physical universe, it is unknown exactly when it was first discovered and applied by mankind. It is reasonable to assume that it has perhaps been discovered and rediscovered throughout history, which explains why it goes under several names.

Uses in architecture potentially date to the ancient Egyptians and Greeks. It appears that the Egyptians may have used both pi and phi in the design of the Great Pyramids. The Greeks are thought by some to have based 
the design of the Parthenon on this proportion, but this is subject to some conjecture.

Phidias (500 BC - 432 BC), a Greek sculptor and mathematician, studied phi and applied it to the design of sculptures for the Parthenon.

Plato (circa 428 BC - 347 BC), in his views on natural science and cosmology presented in his "Timaeus," considered the golden section to be the most binding of all mathematical relationships and the key to the physics of the cosmos.

Euclid (365 BC - 300 BC), in "Elements" referred to divide a line at the $0.6180399 .$. point as "dividing a line in the extreme and mean ratio." This later gave rise to the use of the term mean in the golden mean. He also linked this number to the construction of a pentagram. The Roman architect Vitruvius lived in the 1st century BC and is referred to as the "first engineer in the world". He based his buildings on the proportions of an ideal human body, where the height is equal to the opening of the hands and is eight times the size of the head. He didn't use $f$ at all, whether or not Phidias had ever used it in a similar way. The Fibonacci Series was discovered around 1200 AD. Leonardo Fibonacci, an Italian born in 1175 AD (2), discovered the unusual properties of the numerical series that now bear his name, but it's not certain that he even realized its connection to phi and the Golden Mean. His most notable contribution to mathematics was a work known as Liber Abaci, which became a pivotal influence in adoption by the Europeans of the Arabic decimal system of counting over Roman numerals. (3) It was first called the "Divine Proportion" in the 1500's Leonardo Da Vinci provided illustrations for a dissertation published by Luca Pacioli in 1509 entitled “De Divina Proportione” (1), perhaps the earliest reference in literature to another of its names, the "Divine Proportion." This book contains drawings made by Leonardo da Vinci of the five Platonic solids, also known as regular polyhedra. The Renaissance artists used the Golden Mean extensively in their paintings and sculptures to achieve balance and beauty. Leonardo Da Vinci, for instance, used it to define all the fundamental proportions of his painting of "The Last Supper," from the dimensions of the table at which Christ and the disciples sat to the proportions of the walls and windows in the background. Leonardo da Vinci taught us that if the height of any person is divided by the height of his belly button, the result will be equal to f. 1700 years earlier Euclid had been involved with him but the books referring to him are not mainly mathematical books. They are books inspired by mysticism and tell us about the fuchsia that had been preserved as a relic by ancient mystics, telling us that $f$ is a secret of beauty that has been preserved and that it is no coincidence that the Parthenon's facade is inscribed in gold rectangle with sides having ratio f. In European tradition, the term "golden section" appears in Leorardo da Vinci's work in Latin as sectio aurea. The gold of the "F" symbol appears much later after the suggestion of American mathematician Mark Barr. He proposed it as the original of the sculptor's name Pheidia, who used the gold cut in his drawings. Johannes Kepler (1571-1630), discoverer of the elliptical nature of the orbits of the planets around the sun, also made mention of the "Divine Proportion," saying this about it: "Geometry has two great treasures: one is the theorem of Pythagoras; the other, the division of a line into extreme and mean ratio. The first we may compare to a measure of gold; the second we may name a precious jewel." The term "Golden Ratio" was coined in the 1800's.

It is believed that Martin Ohm (1792-1872) was the first person to use the term "golden" to describe the golden ratio. In 1815, he published "Die reine Elementar-Mathematik" (The Pure Elementary Mathematics). This book is famed for containing the first known usage of the term "goldener schnitt" (golden section). The term "Phi” was not used until the 1900's.

It wasn't until the 1900's that American mathematician Mark Barr used the Greek letter phi $(\Phi)$ to designate this proportion. This appeared in the "The Curves of Life" (page 420) in 1914 by Theodore Andrea Cook. By this time this ubiquitous proportion was known as the golden mean, golden section and golden ratio as well as the Divine proportion. Phi is the first letter of Phidias (1), who used the golden ratio in his sculptures, as well as the Greek equivalent to the letter " $F$," the first letter of Fibonacci. Phi is also the 21st letter of the Greek alphabet, and 21 is one of numbers in the Fibonacci series. The character for phi also has some interesting theological implications. On the other hand, Golden triangle is called any isosceles triangle in which the ratio of the long side to the small will be equal to $\mathrm{f}$, whilst the golden rectangle has a ratio of sides equal to Phi.

\section{Descriptive Geometry}

Most engineers and designers in the day-to-day production of their work use the representation methods offered by Descriptive Geometry, even when this is not done consciously and much more with clear knowledge of geometric laws.

The 3D Euclidean space and everything it contains are essentially identical to the space under construction of the 3D engineer's work, while the well-known "drawings", though usually empirically based on Descriptive Geometry, provide the information required for complete defining the work through reading and understanding its two-dimensional representations. The first foundational ideas for good pair-level projections relate to problems with fortifications, whose solutions required complex and lengthy calculations. Gaspard Monge (1746 - 1818) tackled these problems in an extremely inspiring way when he became a student at the Mezieres law school and there he developed the basic principles of the method by 
studying the proper projection of a three-dimensional object on two projection levels, perpendicular to each other. Cundy, (1981), Papelier (1960), Monge, (1799). The well-known pair of floor-to-ceiling pairs of a building, which constitute the main part of an architectural design, is essentially an application of Monge's orthographic projection.

This method, however, has the disadvantage that the pair of two right projections does not correspond only to one solid unless the solid is convex and, of course, most building projects cannot be modeled as convex solids.

The spelling method is essentially a sub-case of the axometric method which in turn belongs to parallel projection methods.

Axonometry, although appearing as a parallel projection in prehistoric times with rock paintings and has been practiced empirically since ancient times, was organized in the early 19th century.

The term axonometry first appeared in 1852. The basic theorem of axonometry (the existence theorem) was first introduced in the form of conjecture in 1853 by the German mathematician and professor of the Freiburg School of Miners Karl Polke (1810-1876). In 1860 he was published without proof in his book "Darstellende Geometrie". There has been much evidence since then of this theorem, first in 1863 by Herman Amandus Schwartz (1843 - 1922). The axial projection differs from the right projection in that the object is tilted or rotated so that the fronts can also display the invisible sides of the object, (Aubert 1996, Martinuzzi 1999).

In the method of axonometry, therefore, in contrast to the orthographic method, it is sufficient to have a single representation of the three-dimensional object in order to determine all its properties. That is to say, this representation (parallel projection) provides all the information necessary for its clear and complete identification, and therefore for its construction. This is done because this method has a built-in orthogonal system of axes, where each point of the three-dimensional object corresponds to three coordinates $(\mathrm{x}, \mathrm{y}, \mathrm{z})$, with which we can achieve the desired construction of the three-dimensional object. Isometric drawings are divided into isometric drawings and oblique drowings. Isometric drawings are considered to be the most important axometric drawings. Isometric means, of equal measure. For example, if we are isometrically representing a cube, we give such a slope that the lines defined by its edges become axes that form even angles. In general, in order to draw isometric, we first need to draw the three axes which must necessarily form equal angles with each other. The design of the oblique designs is basically the same as the isometric designs, but there are some differences. First, we select the side of the object to be drawn in the actual size and then specify the scale to be used for all lines. Then we can draw an object whose dimensions are equal to the measurements of its outline in its natural size. The lateral axes are usually designed at constant angles of 30, 45 and 60 degrees. [see Fig. 1]

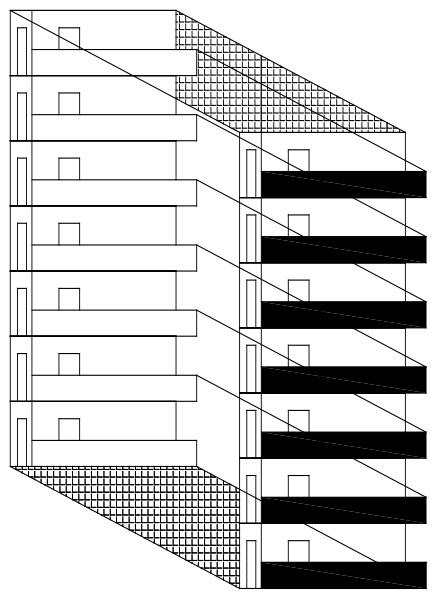

Figure 1. Typical isometric projection

But what matters most is this: as one plans to project an object on a plane, that is, on paper or on a computer screen, one can imagine the position and properties of that object in space at the same time. The best way to achieve this, if it is not inherent, is to make an empirical axonometric - isometric drawing of the object in a sketch form, starting with simple everyday objects. We emphasize that the axial representation of an object is the most faithful representation of the real object because there is a proportion to the distortions of its dimensions, as opposed to the perspective representation that all depends on the position of the observer. In addition, the isometric design of an object can produce its two right projections: plan - face, providing that the designer can, with his imagination, rotate the object in space, so that its projections can be seen correctly. If it cannot do that, there is a proper command in every digital design program. The isometric design of an object also has the following advantage. It is the only way to represent a three-dimensional object on the plane of the paper or computer screen that can be seen and the loads that move or distort it. Therefore, it is also the only method of representation that allows us to pre-design and test the static adequacy of a structural component of a structure if we do not want to confine ourselves to studying cross-section.

\section{Projective Geometry}

In Projective Geometry, which is a non-Euclidean geometry, we accept that the concept of parallelism between two lines is not defined. Projective Geometry arose out of a need, not a practice like Euclidean, but aesthetics. It is the attempt to depict three-dimensional reality in the two-dimensional painting in order to create a sense of depth (perspective) in the recipient. Although the 
solution of this problem was early occupied by ancient Greek artists and mathematicians, we would say that the rules of the Perspective were mainly systematized during the Renaissance, by Leonardo Da Vinci (1483 - 1519), Albert Durer (1471 - 1528), Michelangelo Buonarrotti (1475 - 1564) and Raffaello Santi or Sanzio (1483 - 1520). It is worth noting that many of the great Painters of the Renaissance had serious knowledge of Mathematics and Engineering, so the rules of the Perspective had a mathematical background and formed the basis for the later development of Projective Geometry, Cremona
(1962), Norling (1999), Parrens (1997).

Now, let us focus on the process of capturing images in the painting. For facility reasons, we assume that the last one we denote by $\mathrm{P}$ is transparent and perpendicular to the horizontal plane E on which the Painter stands. The image of an E-point $\mathrm{P}$, is the point $\mathrm{P} 1$, which appears as the intersection of the OP-ray, (where $\mathrm{O}$ is the painter's eye, ie the Projection Center), with the plane of the transparent panel II (Projection Plane). The same is true of any other point $\mathrm{Q}$, R etc., of the E-plane and the surrounding space [see Fig. 2].

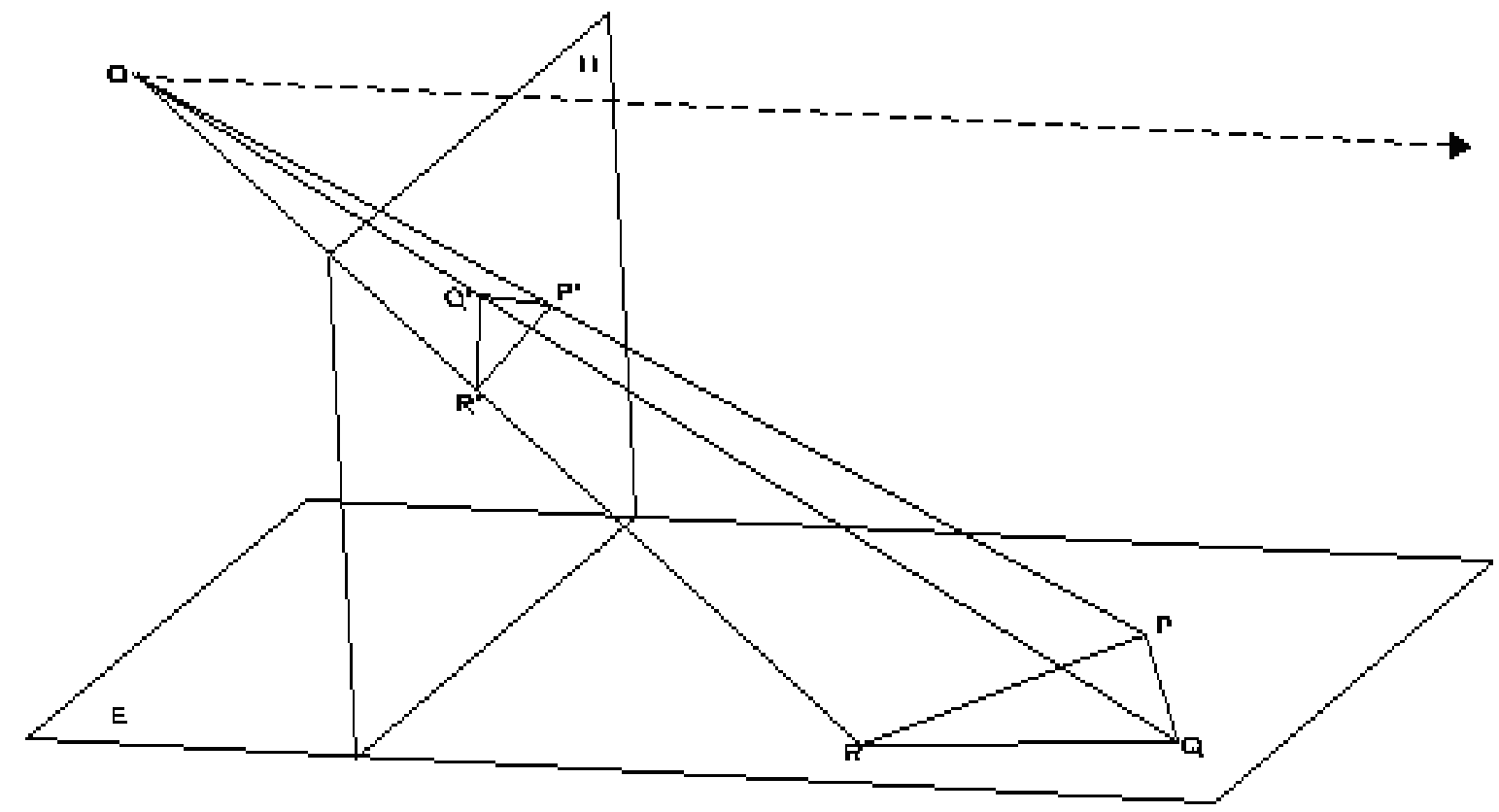

Figure 2. Central projection concept 
Finally, each plane of the Euclidean space corresponds to one and only one line in the projection plane. The complete mathematical description of the experiences of Painting and the rules of Perspective was made in the 17th century, in conjunction with Descriptive Geometry, which was developed to facilitate the engineering needs of Engineering. In later times, decisive for the evolution of projective geometry was the contribution of G. Monge (1746 - 1818), A. Mobius (1760 - 1867), V. Poncelet (1788 - 1867), J. Steiner (1796 - 1863). It is noteworthy that the projective geometry, until about 1850, was considered in the context of Euclidean. The photograph is the most usual example of projective geometry [see Fig. 3].

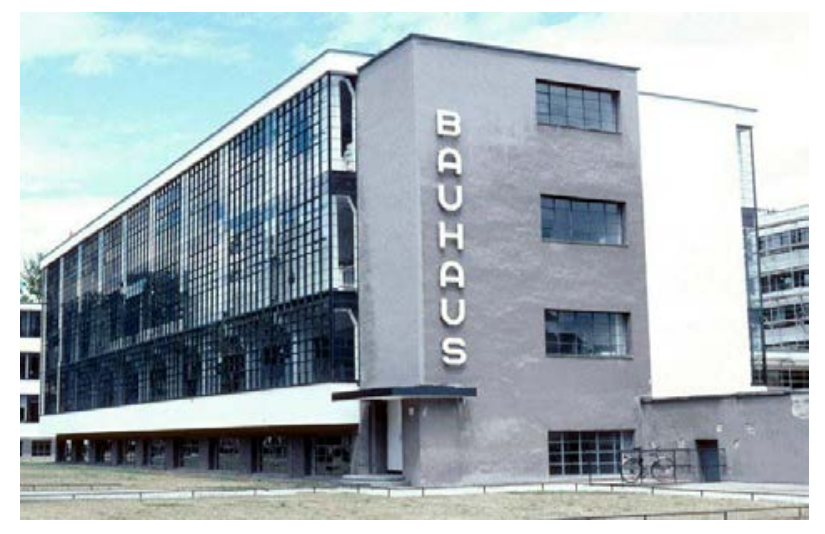

Figure 3. photograph - the most trivial example of projective geometry

On the other hand, in projective geometry, Desargues's theorem, named after Girard Desargues, states that:

"Two triangles are in perspective axially if and only if they are in perspective centrally."

Here we shall give a general method for projecting convex polygons in the framework of Desargues's theorem, Cromwell (1997). This useful and practical method can be summarized in the following steps:

Step 1

Numbering of solid nodes

Step 2

Jointing of nodes and separation of solid into triangles

Step 3

Design of lines belonging to the Central Projection of Solid Nodes

Step 4

Random line selection intersecting the lines defined by the formed triangles

Step 5

From the first intersection point we draw a straight line and find the first homologous side of the first perspective triangle located between its central projections side of the original triangle.

Step 6

We find the homologue of the second (consecutive) side of the triangle and so on. Note that we project triangles. The final solid will emerge on its own. [See Fig. 4]

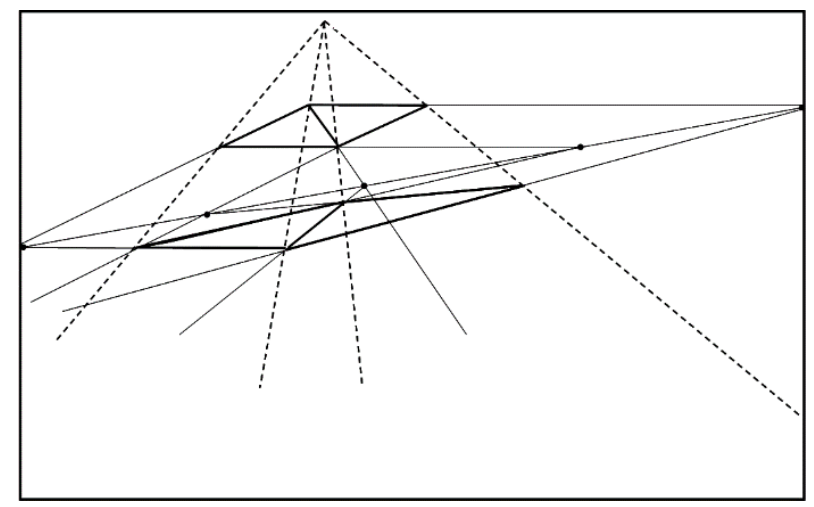

Figure 4. Application of Desargues's theorem in projective geometry

\section{0th Century. The role of applied mathematics and design technology}

The term CAD was originally used for computer-aided design. Then he developed into CADD (Computer Aided Drafting and Design - Computer Aided Design and Design). Today CAD means both. CAD systems can be used for many design forms. The drawing is displayed on the computer screen as the designer creates it. The designer can, through the CAD program, intervene in the final design and make changes and modifications. The way CAD systems work depends on the software. Although the commands and procedures vary depending on the program, they allow designers to create drawings in two or three dimensions, modify them, save them and print them exactly as they would with a text file, Bézier (1978), Coxeter (1974), Blinn (1982), Ball (1987) CAD differs from traditional design in many ways. In traditional design, for example, you definitely need the ability to draw lines and write letters of the correct size. For the CAD system, this capability is not considered important.

The system, produces letters and lines much more evenly than even the best traditional designer, Dunn (2012), Strud, (2006), Fejes, (1964), Johnson (1966). Here, however, we should emphasize how what is truly irreplaceable in both conventional and digital design is the synthetic ability of the designer as well as his sharpened geometric perception and overall perception of space. If one does not have these, even if they are fully aware of the environment of a CAD software, they will not be able to develop initiatives and solve original problems. Generally, CAD systems enable their users carried out the following procedures:

- They draw lines as required in any position of any size or shape. 
- They design circles and arcs of any size

- Move or duplicate part of the drawing or even the whole drawing and place it on another part of the screen.

- They define the scale for a plan and maintain that scale for the design of details.

- Calculate distances and display the dimensions automatically.

- They check the accuracy of the dimensions.

- They design a symmetrical pattern, creating a mirror image of what is designed.

- They automatically create views and intersections in a spell-checker.

- They incorporate old designs into new designs according to "raster to vector" techniques.

- They save or print drawings.

On the other hand, given that CAD is capable of producing an infinite array of astounding images, it seems bizarre that someone still takes time to write about the architectural plan, such an apparently commonsense, if not trivial, spatial description. The argument given in what follows is intended to set up a recollection of the topological properties of the architectural plan in the operative domain of the discipline. More than its acknowledgement as a basic element in the definition of geometrical order, it is intended in what follows to reinstate the value of the plan as a crucial element in the understanding of the experiential dimension of architecture. Nonetheless, one could give a provisional mathematical definition of a fractal as a set for which the Hausdorff dimension strictly exceeds the topological dimension, once these terms are defined. Yet, this is not entirely satisfactory as it excludes sets one would consider fractals [Benoit 1975]. Mandelbrot introduced the term fractal in 1977, based on the latin noun "fractus", derived from the verb "frengere" meaning "to break". The idea of fractional dimension had a background that dated back to more than a century before Mandelbrot's works [Benoit 1975, Brambila-Paz 2017]. As it was already mentioned, fractal geometry is the study of mathematical shapes that display a cascade of never ending, self-similar, meandering details as one observes them more closely. On the other hand, self-similarity is a phenomenon where repeated elements change in scale but retain a similar shape. The most common examples of fractals are the fern leaf, clouds, coastline, branching of a tree, branching of blood vessels, etc. Georg Cantor (1845-1918) evolved his fractal from the theory of sets. All the real numbers in the interval $[0,1]$ of the real line are considered. The interval $(1 / 3,2 / 3)$ which constitutes the central third of the original interval is extracted, leaving the two intervals $(0,1 / 3)$ and $(2 / 3,1)$. This process of extracting the central third of any interval that remains is continued ad infinitum. Moreover, the role of Boolean matrices and planar graphs theory in architectural design, was thoroughly examined by Palla 2003. Specifically, the top view of the architectural form may emerge as a succession of finite planar graphs by means of Demoucron algorithm, Palla, (2003) [see Fig. 5].

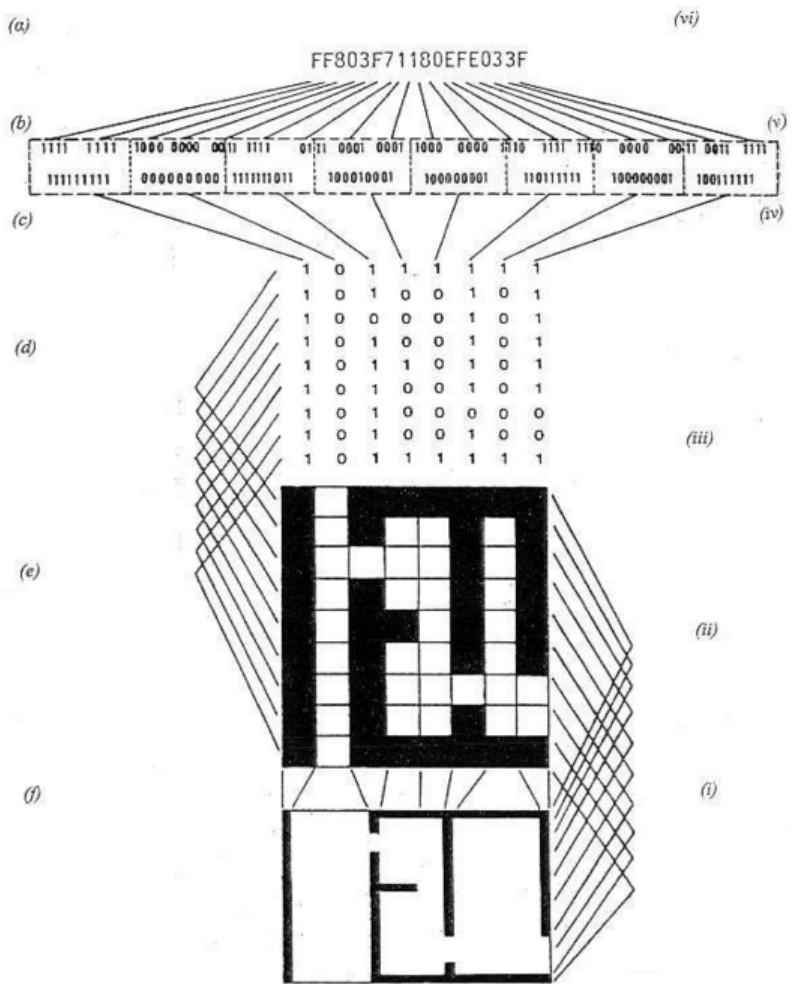

Figure 5. Application of Demoucron algorithm to bulding design, Palla (2003).

Further, the use of Demoucron algorithm can be also extended to the architectural and urban design of city blocks Palla, (2003) [see Fig. 6].

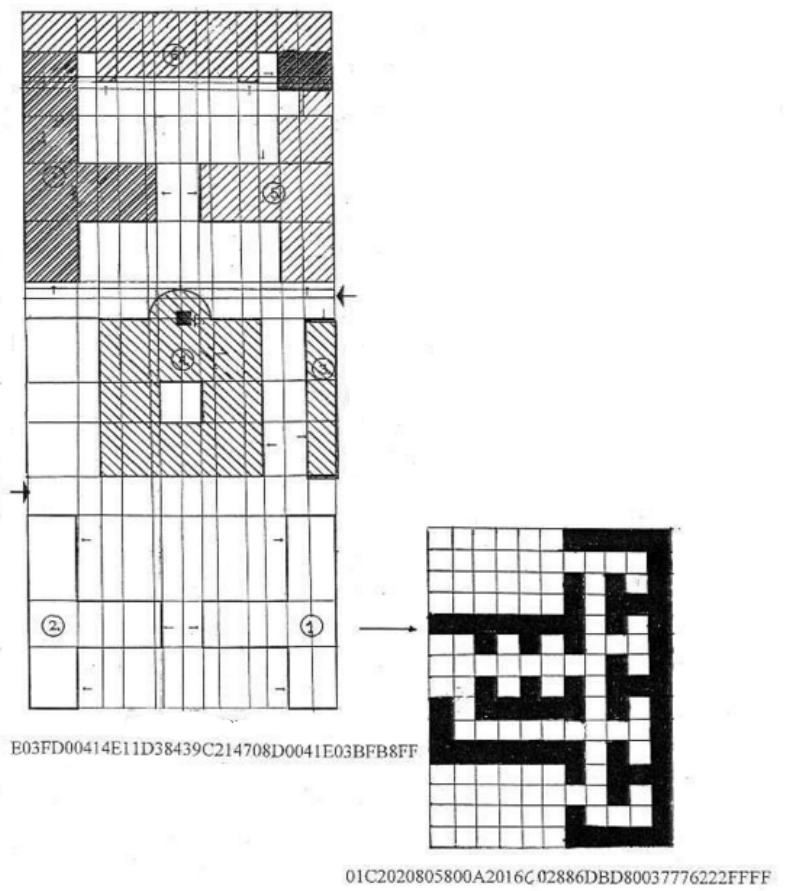

Figure 6. Application of Demoucron algorithm to urban design, Palla (2003). 
In graphic architecture thought, geometry usually appears as an instrumental support for project speculation. Geometric procedures are presented as representational resources for the graphic testing of reflection and for the exposition of ideas in order to build a logical order as regards representation. The fast rise of computing in the last decades has made it possible for architects to work massively and in a graphic and intuitive way with mathematical representations of three-dimensional geometry, such as the NURBS. These organic surfaces of free shapes defined by vector curves have allowed access to a rapid generation of complex shapes with a minimum amount of data and of specific knowledge. The great development of modeling achieved by the digital media and the limitations in the technical and building areas and in the existence of materials which are coherent with the resultant shapes reveals a considerable distance between the systems of ideation and simulation characteristic of the computing era and the analogous systems of production inherited from the slow industrial development. This distance has been shortened by CAD/CAM systems, which are, however, not very accessible to the architectural field. If we incorporate to the development of these divergent media and the limitations which are distinctive of the material resources and procedures of the existent local technology, the aforementioned distance seems even greater.

\section{Discussion}

The building design obviously constitutes a combination of both the geometry of the structural members and architectural form along with the choice of materials. Here one should elucidate that "Geometric consciousness" is something that is generally approached by all application engineers to a very large extent through intuitive approach, and without the concept of proof with a rigorous mathematical process. Thomas Hughes in the monumental work of American Genesis spoke about the second discovery of America by Europeans in the 20th century through familiarization with the American technological model. European engineers, architects and artists are inspired by American electrical systems, manufacturing plants cars, management systems. Essentially, these influences were also the constituent features of the Modern Movement.

On the other hand, the French model of high education of engineers and architects founded the Prussian Bauakademie in 1799. The Academy trained civil engineers and architects and her graduates were not named engineers (Ingenieure) but Baubeamte. In fact, this school had configured according to the model and requirements of public services and produced the necessary technical staff to staff the public sector construction, roads, bridges, canals and later railways.
Certainly, the relationship between architectural design and geometry starts with the notion of harmony as the principle for all sciences and creations. The analysis of the antique comprehension of harmony shows the geometrical root and the superior idea of this concept for all sciences and designing disciplines. Today the various sciences and arts are in most cases strongly separated. Nonetheless, students who go to university schools with content in art direction are in dire need of developing 'geometric consciousness and geometric imagination' to understand the concept of 'geometrical space', which is obviously the actual domain of their science and their professional applications every day. Yet, the only ones who are not responsible in this case are the high school students. To the best of author's knowledge, their technical perception, as well as their synthetic ability and perception of three-dimensional space, both theoretically and practically, have never been tested in General or Unified High Schools in order to enter an Art School. By focusing on French model of art education which seems to be the most convenient one in west civilization, one should definitely refer to Ecole des Beaux Arts. The origins of the school go back to 1648 when the Académie des Beaux-Arts was founded by Cardinal Mazarin to educate the most talented students in drawing, painting, sculpture, engraving, architecture and other media. Louis XIV was known to select graduates from the school to decorate the royal apartments at Versailles, and in 1863 Napoleon III granted the school independence from the government, changing the name to "L' École des Beaux-Arts". The architecture department was separated from the École after the May 1968 student strikes at the Sorbonne. The name was changed to École nationale supérieure des Beaux-Arts. The high scientific prestige of the Grandes Écoles d'Ingénieurs model, where Joseph Mc Louis Louis Lagrange's Mécanique analytique was first taught, as well as the representational geometry (mainly the Monge method, but also the Pohlke-Schwarz method), is something which could be an example to be imitated in other countries of the so-called Western culture, although the Anglo-Saxon countries have made several objections to the issue. In this sense, for the past three decades, English-speaking major international universities are in the United States, the United Kingdom, Australia, and New Zealand, and in the last decade, Asian universities have adopted educational programs that tackle university education holistically, that is, to provide study programs which along with knowledge enhance students' personal skills and abilities. This is evident either through actions they take or through parallel actions with learning, and as stated in the principles they adopt and apply to quality assurance / certification. Quality assurance in USA is ensured in a very stringent manner which among many parameters that examines on a regular basis, counts on the plus strengthening of a series of technical and personal skills of students, as they result from learning outcomes 
and objectives that teachers teach and schools / institutions formulate. On the other hand, in Europe, such initiatives are moving slowly, mainly with a bureaucratic perception of quality, and not as a substantial process of education because university institutions, with the exception of the Anglo-Saxon ones, are finding it difficult to meet the challenge of the time, simply educated but accomplished personalities with vision, goals, values, that is, those who will innovate with their ideas, will handle difficult global problems such as climate change water and food shortages, but also problems that do not exist today and will appear in the future.

\section{Conclusions}

It is widely accepted amongst the members of the scientific community that a strong theoretical background in mathematics remains unchanged during rapid technological advances.

By taking into account the strong historical relations between geometry and architectural design, we help to keep the background of west civilization culture but also to understand the fruitful combination between geometrical thinking and architectural designing. Indeed, modeling in appropriate software packages accelerates the design process. Time saving is of great significance to each architect, which strives to choose the best possible modeling program. But what about the other fine arts?

According to the above study, the following two firm conclusions can be drawn:

i) Separation of architectural schools into technological and art schools corresponding to the French standard of study.

ii) In this framework, we can talk about the well-known French model, of Grandes Écoles d'Ingénieurs with high theoretical requirements in mathematics as well as elite sets of state engineers but also for its engineers graduates of Arts et Metiers and specialty industrial schools who they were founded in the late 19th and early 20th centuries. Such a model should be extended to all Schools of Fine Arts in west civilization countries.

Finally, it can be said that the most appropriate mathematical background for architectural studies is a very difficult issue. Here, we would like to emphasize that in addition to the formal course required through studies in Architectural Schools, their relevance to the current and future economy plays a very important role, and consequently in its society and sustainability, which is an economy that is inextricably linked to the inspiration and innovation for solutions to current or future unknown items, the design of new products, etc.

In this framework, if one takes also into account the fact that the knowledge which architects acquire today is outdated in a very short time, then we should be seriously concerned. In addition, many of the architectural work will exist in the future today we have not even imagined. Hence it seems that what is being sought internationally are those studies that will provide the necessary knowledge, skills and abilities that are necessary for the challenges of the future and can ensure a relatively easy adaptation of architect graduates who have the knowledge of yesterday and today in tomorrow, at a time of dramatic changes.

\section{Conflict of Interest}

The author declares that there is no conflict of interest regarding the publication of this paper.

\section{Sources of Financial Funding and Support}

The author confirms that there are no sources of financial funding and support concerning this work.

\section{REFERENCES}

[1] C. Leopold: Geometry Concepts in Architectural Design. Proc. 12th Internat. Conf. on Geometry and Graphics. Salvador/Brasil 2006.

[2] Corbusier, Le: Der Modulor. Deutsche Verlags-Anstalt, Stuttgart 1956, 7th ed. 1998

[3] Popescu, M., Vernacular architecture as a source for national architectural identity: Ion Mincu and Károly Kós, Transylvanian Review Vol. 24, Issue 2, 2015, Pages 43-48

[4] N. Palla Boolean matrices - graphs computer - science Ph.D.

Thesis in NTUA, NTUA, 2003 http://hdl.handle.net/10442/ hedi/19704

[5] D Aguiar Elements of topology in the architectural plan. In: Proceedings of the 37th Australia \& New Zealand architectural conference, Sydney: 2003.

[6] Chiarella, M., 2004. Geometry and Architecture: NURBS, Design and Construction, Proceedings of the Fourth International Conference of Mathematics 53 \& Design, Special Edition of the Journal of Mathematics \& Design, Volume 4, No.1

[7] Gül Ö. (2015). A Study on instructional methods used in CAD courses in interior architecture education, Procedia Social and Behavioral Sciences 174, pp. 1758 - 1763

[8] Kitchley, J. L.: Fractals in architecture, Architecture \& design, 20, 42-48 (2003)

[9] Choisy A. «Histoire de l' Architecture Tome II» Bibliotheque de l’ Image Paris 1996

[10] Fletcher B. «A History of Architecture» Architetural Press 
1998

[11] R. Recht: Le dessin d'architecture. Société nouvelle Adam Biro. Paris 1995. Italian edition Editoriale Jaca Book, Milano 2001.

[12] Cundy H.M., Rollet A.P. Mathematical Models, Third ed. Tarquin, Stradbroke, 1981

[13] Papelier G. «Precis de geometrie» Descriptive Libraire Vuibert Paris 1960

[14] G. Monge: Geometrie Descriptive. Leçcons données aux Ecoles Normales par Gaspard Monge (1794). Badouin, Paris 1799.

[15] Aubert J. «Axonometrie» Les Editions Dela Villette Paris 1996

[16] Martinuzzi M. «Axonometrie» Ecole d' Architecture, Monpellier 1999

[17] Cremona L. «Elements of Projective Geometry» Dover Publications New York 1962

[18] Norling R.E. «Perspective Made Easy» Dover Publications New York 1999

[19] Parrens L. «Traite de Perspective» d’ Aspect Evrolles Paris 1997

[20] Cromwell, P. R. Polyhedra (Cambridge University Press, 1997).
[21] Ball W.W., Coxeter H.S. Mathematical recreations and essays 13th ed. Dover New York 1987

[22] Bézier P. General distortion of an ensemble of biparametric patches. Computer Aided. Design, 10(2):116-120, 1978

[23] Blinn, J. F., A Generalization of Algebraic Surface Drawing, ACM Transactions on Graphics, 1(3), July 1982, pp. 235-256.

[24] Coxeter H.S. Projective Geometry 2nd ed. Springer Verlag, 1974

[25] N. Dunn, Digital Fabrication in Architecture, Lawrence King Publishers, London, 2012 26-39

[26] Fejes Toth. L. Regular Figures Pergamon Press Oxford 1964

[27] Strud I. Boundary Representation Modelling Techniques, Springer London 2006

[28] Johnson N. W. Convex Polyhedra with Regular Faces Canada J. Math. 18169 - 2001966

[29] Benoit B. Mandelbrot, Les objets fractals: forme, hasard et dimension, Paris: Flammarion, Nouvelle bibliothèque scientifique1975. - $190 \mathrm{p}$.

[30] F. Brambila-Paz, editor. Fractal Analysis - Applications in Physics, Engineering and Technology. BoD-Books on Demand, 2017. 